\title{
CCR2-V64l polymorphism is associated with increased risk of cervical cancer but not with HPV infection or pre-cancerous lesions in African women
}

\author{
Koushik Chatterjee1, Collet Dandara², Margaret Hoffman³ and Anna-Lise Williamson*1,4
}

\begin{abstract}
Background: Cervical cancer, caused by specific oncogenic types of human papillomavirus (HPV), is the second most common cancer in women worldwide. A large number of young sexually active women get infected by HPV but only a small fraction of them have persistent infection and develop cervical cancer pointing to co-factors including host genetics that might play a role in outcome of the HPV infection. This study investigated the role of CCR2-V64I polymorphism in cervical cancer, pre-cancers and HPV infection in South African women resident in Western Cape. CCR2-V64l polymorphism has been previously reported to influence the progression to cervical cancer in some populations and has also been associated with decreased progression from HIV infection to AIDS.

Methods: Genotyping for CCR2-V64/ was done by PCR-SSP in a case-control study of 446 women (106 black African and 340 mixed-ancestry) with histologically confirmed invasive cervical cancer and 1432 controls (322 black African and 1110 mixed-ancestry) group-matched (1:3) by age, ethnicity and domicile status. In the control women HPV was detected using the Digene Hybrid Capture II test and cervical disease was detected by cervical cytology.

Results: The CCR2-64/ variant was significantly associated with cervical cancer when cases were compared to the control group $(P=0.001)$. Further analysis comparing selected groups within the controls showed that individuals with abnormal cytology and high grade squamous intraepitleial neoplasia (HSIL) did not have this association when compared to women with normal cytology. HPV infection also showed no association with CCR2-64/ variant. Comparing SIL positive controls with the cases showed a significant association of CCR2-64/variant $(P=0.001)$ with cervical cancer.

Conclusions: This is the first study of the role of CCR2-V64/ polymorphism in cervical cancer in an African population. Our results show that CCR2-64/variant is associated with the risk of cervical cancer but does not affect the susceptibility to HPV infection or HSIL in South African women of black and mixed-ancestry origin. This result implies that the role of CCR2 is important in invasive cancer of the cervix but not in HPV infection or in the development of pre-cancers.
\end{abstract}

\section{Background}

Cervical cancer is the second leading cause of cancer and cancer related mortality in women worldwide with 493,243 cases and 273,505 deaths per year [1]. The incidence and mortality rates have dropped significantly in developed countries due to effective cervical screening

\footnotetext{
* Correspondence: anna-lise.williamson@uct.ac.za

1 Division of Medical Virology and Institute of Infectious Disease and Molecular Medicine (IIDMM), University of Cape Town, Cape Town, Republic of South Africa

Full list of author information is available at the end of the article
}

programs thus $83 \%$ of all new cervical cancer cases and $85 \%$ of all cervical cancer-related deaths now occur in developing countries where screening programs are poor [2]. Cervical cancer is the most common cancer and the highest cause of cancer death in women in sub-Saharan Africa accounting for $22 \%$ of all cancers in women [3].

Squamous cell carcinoma of the cervix arises from the pre-cancer lesions of squamous intraepithelial lesions (SIL) [4] which are further divided into low-grade (LSIL) and high-grade (HSIL) stages. LSILs are pre-cancerous 
and considered as the very early precursor stages of cervical cancer with very few cases progressing to cancer [5] while most HSILs progress to invasive cervical cancer (ICC) when left untreated [6]. Cervical cancer is a multistep process that develops slowly over several years after persistent infection of epithelial cells with oncogenic types of human papillomavirus (HPV), mainly types 16 and 18. Many women become infected with HPV during their life-time but most are able to clear the infection. Less than $1 \%$ of the clinically detectable HPV infections progress to cervical cancer [7]. This indicates that additional risk factors play an important role in the development of the cancer of the cervix. These risk factors include host and viral genetic factors as well as environmental and life style factors [8]. The possibility of genetic predisposition is strengthened by the observation of a double risk of developing cervical cancer in biological first degree relatives [9] with these factors most likely influencing response to HPV infection and its persistence. The involvement of macrophages, natural killer (NK) cells and T-cells in papilloma regression further point to the role of genes associated cell-mediated immunity (CMI) in the risk of infection and persistence of HPV [8]. Data showing increased incidence of SIL in immusuppressed women and in immunocompromised patients as well as in immunomanipulated animal models show a strong role of the immune system in controlling the infection $[7,10]$.

One of the earliest responses of human body to injury or infection is the release of chemokines that triggers recruitment of local inflammatory and immune cells. Chemokines are chemoattractant cytokines that regulate migration of leukocytes by binding to G-protein coupled cell-surface receptors. It has been postulated that HPV disrupts the interaction between epithelial cells and the immune system by deregulating the expression of chemokines which can be mediated by (HPV) E7 which interacts with IRF-1 [11].

Chemokine receptor 2 or CCR2, has affinity for CCL2 (monocyte chemoattractant protein-1 (MCP-1)), CCL7, CCL8 and CCL13 ligands and is expressed on basophils, monocytes, dendritic cells (DCs), activated T-cells and NK cells. CCR2 is a major receptor for the MCP-1 which is produced largely by tumour cells $[12,13]$ and is responsible for recruiting macrophages to tumours in bladder, cervix, ovary, lung and breast. The role of macrophages in tumour development and control is multifactorial. In early stages, macrophages have tumour cytotoxic characteristics but once tumour cells have evaded the immune system they switch to play a role in tumour angiogenesis [14-16]. A pilot study done by Riethdorf et al. (1996) showed that $1 / 6$ high grade squamous intraepithelial neoplasia expressed MCP-1 compared to 4/5 squamous cell cervical caracinomas [17] suggesting that $\mathrm{MCP}-1$ plays a greater role in invasive cancers compared to pre-cancers. This was further confirmed by in situ hybridisation studies [18] where MCP-1 expression was detected in the stoma surrounding the tumour particularly at the invasion front.

CCR2 gene is localized on chromosome 3p21 within a cluster of chemokine receptor genes. It has two isoforms; CCR2A and CCR2B products of the CCR2 gene as a result of alternative splicing. A single nucleotide polymorphism (SNP) of G to A at position 190 of CCR2 gene changes amino acid valine (GTC) to isoleucine (ATC) at codon 64 (CCR2-V64I). This conservative amino acid change takes place in the first transmembrane domain of CCR2A and CCR2B [19]. This change makes CCR2A more stable and increases its half-life but does not in any way affect the stability of CCR2B isoform [19]. The CCR2-V64I polymorphism has been extensively studied and several reports show an association of the CCR2-64I variant with reduced risk of progression to AIDS in HIVinfected individuals, [20-23], multiple sclerosis [24] and development of breast cancer [25]. It is also associated with increased risk of carotid atherosclerosis [26] and reduction in the risk of renal transplant rejection [27].

There are conflicting reports on the role of the CCR2V64I polymorphism in the development or risk to cervical cancer [28-31]. A study comparing SIL patients to ICC patients in a Portuguese population reported that the CCR2-64I variant was associated with reduced risk of developing ICC from HSIL [29]. The same group conducted a case-control study in the same population comparing women with HSIL to a control group and found CCR2-64I variant as a risk allele for developing HSIL [28]. Among two studies in Swedish population the first study [30] reported that the CCR2-64I variant was associated with decreased risk of developing cervical cancer. The second Swedish study did not find any association of CCR2-64I variant with either HPV infection or cancer of the cervix [31].

Epidemiological studies have demonstrated the importance of host genetic susceptibility factors in the development of cervical cancer. A twin study [32] and a motherdaughter family study [33] demonstrated a hereditary component of cervical tumours. Biological first-degree relatives of women with cancer of the cervix showed an increased risk of developing cervical cancer compared to non-biological relatives of women with cervical cancer [9]. There are conflicting reports on the role of the CCR2V64I polymorphism in cervical cancer and furthermore, none of these studies have been done in African population, thus, we therefore investigated the role of CCR2V64I polymorphism in risk of cancer of the cervix in South African women of black and mixed-ancestry origin. 


\section{Methods}

\section{Participants}

A total of 1878 subjects comprising 446 women with invasive cervical cancer (106 black African and 340 women of mixed-ancestry) and 1432 controls (322 black African and 1110 women of mixed-ancestry) without cancer of the cervix were recruited in a cross-sectional study. Incident cases of symptomatic invasive cervical epithelial cancer (stage 1b-IVb), diagnosed a maximum of six months previously were recruited from Groote Schuur Hospital and Tygerberg Hospital in the Western Cape Province, South Africa. Hospital controls were series matched in a ratio of 3:1 to the cases on decade of age, ethnic group and area of residence (urban/rural). Most of the Black African subjects originally came from either the Transkei, in the Eastern Cape of South Africa while their Mixed Ancestry group refers to a group of people that show highest level of intercontinental admixture of any global population resulting from gene flow between Black Africans, Western Europeans, Khoisans, Indians, East Asians (eg. Malaysians) and Cushitics who settled in the Western Cape region [34]. There were 264 (59\%) urban cases and 182 (41\%) rural cases compared to 718 (53\%) urban controls and 632 (47\%) rural controls (residency status was not known for 82 controls). The cases and controls formed part of a study to investigate the association of oral contraceptives with cervical cancer $[35,36]$.

The mean age for black cases was 43.8 yrs (SD 9.2) and for mixed-ancestry cases it was 46.0 yrs (SD 8.1). The mean age for black controls was 42.3 yrs (SD 9.0) and for mixed-ancestry controls it was 44.3 yrs (SD 8.4). The HIV infection status was $4.8 \%$ for the cases and $4.7 \%$ for the controls. No significant differences in age or HIV status were observed between cases and controls (data not shown here). A significant difference in the distribution of the smoking status was found between the cases and the controls $(\mathrm{P}=0.004)$ (data not shown here). Subsequently, all the analyses were adjusted for the smoking status along with ethnicity. The observed genotype frequencies for CCR2-V64I polymorphism in the controls were not in Hardy-Weinberg equilibrium $(P=0.001)$ (data not shown here). This could be due to the fact the our controls were not a randomly chosen population rather handpicked in a 3:1 matched ratio to the cases on decade of age, ethnic group and area of residence (urban/ rural).

\section{Clinical specimens}

Blood was collected from cases and controls, following written informed consent and stored at $-80^{\circ} \mathrm{C}$. The genetic study was approved by the University of Cape Town Human Ethics Committee (REC REF: 075/2009).
The subject identifiers were permanently unlinked from the specimens.

\section{Papanicolaou test}

Endocervical scrapings were taken from the control women to conduct papanicolaou test (Pap smear) to check for their cytology status as previously described [35]. For this paper samples positive for ASCUS (atypical squamous cells of undetermined significance), LSIL or HSIL were considered as abnormal cytology.

Among 1258 controls for which pap smear results were available, 185 (15\%) were positive. Of the 185 pap smear positive samples, 91 (49\%) were classified as SIL and the remaining 94 (51\%) were classified as ascus (Atypical Squamous Cells of Undetermined Significance) positive. Among those 91 SIL positive samples, 46 (51\%) were positive for LSIL and 45 (49\%) were positive for HSIL.

\section{High-risk HPV type detection}

Endocervical scrapings from control women were assayed for HPV infection using the Digene Hybrid Capture II HPV Test for the detection of high risk HPV types $16 / 18 / 31 / 33 / 35 / 39 / 45 / 51 / 52 / 56 / 58 / 59 / 68$ and were classified positive according to the manufacturer's instructions (Digene Corporation, Gaithersburg, MD, USA) [35].

\section{Extraction of genomic DNA}

The genomic DNA was extracted using TotalNucleicAcid Extraction kit for MagNA Pure Compact nucleic acid extractor (Roche Diagnostics, Germany).

\section{Determination of CCR2-V64I polymorphism}

The CCR2-V64I polymorphism was determined by polymerase chain reaction (PCR) using sequence-specific primers (SSP) followed by agarose gel electrophoresis. Two PCR reactions were carried out for each sample using two different forward primers (CCR2-64V and CCR2-64I) and a reverse primer. $130 \mathrm{ng}$ of genomic DNA was amplified in a $10-\mu \mathrm{l}$ reaction mixture containing 10 picomoles of each CCR2-V64I primers: F(CCR2-64V), 5'TGGGCAACATGCTGGTCG3' or F(CCR2-64I), 5'TGGGCAACATGCTGGTCA3' and R, 5'TGGAAAATAAGGGCCACAGAC3' [37] and 5- $\mu \mathrm{l} 2 \times$ ImmoMix $^{\mathrm{Tm}}$ (Bioline). PCR cycle reactions were performed on an ABI 2720 Thermal Cycler (Applied Biosystems, Foster City, CA) beginning with a denaturing step at $95^{\circ} \mathrm{C}$ for $2.5 \mathrm{~min}$ followed by 10 higher-stringency cycles of denaturing at $94^{\circ} \mathrm{C}$ for $25 \mathrm{~s}$, annealing at $60^{\circ} \mathrm{C}$ for $45 \mathrm{~s}$ and extension at $72^{\circ} \mathrm{C}$ for $45 \mathrm{~s}$ again followed by 21 lower-stringency cycles of denaturing at $94^{\circ} \mathrm{C}$ for $25 \mathrm{~s}$, annealing at $58^{\circ} \mathrm{C}$ for $40 \mathrm{~s}$ and extension at $72^{\circ} \mathrm{C}$ for $40 \mathrm{~s}$ with a final extension at $72^{\circ} \mathrm{C}$ for $6 \mathrm{~min}$. The PCR reaction conditions were adapted and modified from Tang J et. al. [37].

The amplified PCR products of 413 base pairs (bp) were analysed by running on $1.5 \%$ agarose gel stained with 
ethidium bromide using an $\mathrm{O}^{\prime}$ GeneRuler $^{\mathrm{ma}} 50$ bp DNA Ladder, ready-to-use (Fermentas Inc, Ontario, Canada). The samples with a wild type allele (G) at position 190 of the CCR2 gene amplified the PCR containing CCR2-64V forward primer and showed no products for the PCR containing CCR2-64I forward primer. Likewise, samples with a mutant allele (A) at position 190 of the CCR2 gene did not show any product for the PCR containing CCR2$64 \mathrm{~V}$ forward primer rather amplified the PCR containing CCR2-64I forward primer. The heterozygous samples showed products for both the PCR containing CCR2-64V as well as CCR2-64I forward primers (Figure 1).

The genotyping was cross-checked by DNA sequencing of total 40 samples, 10 each for wild type, mutant type, heterozygous and 10 randomly selected samples using a forward primer (5'TACGGTGCTCCCTGTCATAAA3') and the same reverse primer previously used for genotyping of CCR2. The DNA sequencing was done using a BigDye Teminator V3.1 Cycle sequencing kit (Applied Biosystems, Foster City, CA) following the manufacturers protocol. Other than the mutant type samples, all the other samples showed $100 \%$ confirmation of our genotype results. Due to some ambiguity in the first 10 randomly selected mutant type samples, we decided to sequence all the mutant samples. Among all the 125 mutant samples (as assigned according to PCR amplification and agarose gel results) only 3 did not show any result in both forward and reverse primer sequencing and were excluded from the final analysis. Rest of the 122 samples showed clear sequencing results of GG, AG or $\mathrm{AA}$ and were scored accordingly.

\section{Statistical Analysis}

The genotype distributions were tested for Hardy-Weinberg equilibrium in cases and controls. Logistic regression was used to test for genotype associations with cervix cancer status as well as baseline characteristics (age, ethnicity and smoking status) and secondary outcomes such as HIV status and abnormal cytology (Pap smear) in the control group. Statistical analyses were done using Stata 9 software.

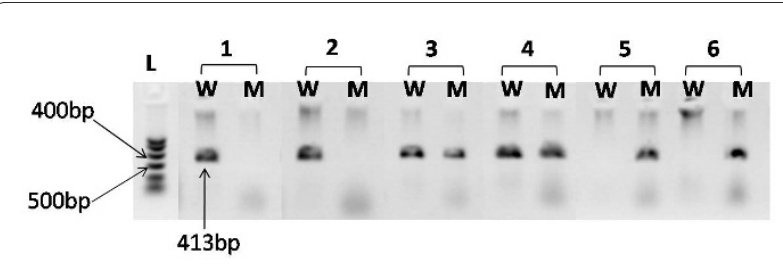

Figure 1 Analysis of the CCR2-V64I genotypes on agarose gel. $L=$ DNA ladder, samples 1 and 2 = GG (CCR2-64V - wild type homozygous), samples 3 and $4=$ GA (CCR2-V64I - heterozygous), samples 5 and $6=$ AA (CCR2-64I - mutant type homozygous), W = PCR amplifying wild type variant (CCR2-64V), M = PCR amplifying mutant type variant (CCR2-64l).

\section{Results}

The role of CCR2-V64I polymorphism was investigated in the risk of cancer of the cervix, pre-cancers and HPV infection in South African women of black and mixedancestry origin.

Genotyping data for CCR2-V64I polymorphism was obtained on 1378 of the 1432 control specimens. The frequency of CCR2-64I variant was 39\% in black cases and $20 \%$ in the black controls and $40 \%$ in mixed-ancestry cases and $18 \%$ in mixed-ancestry controls. A statistically significant, association was found with CCR2-64I variant $(P=0.001)$ and cervical cancer cases and controls after adjusting for ethnicity and smoking (Table 1).

Since cervical cancer is a multi-step process which starts with HPV infection it was of interest to determine at which stage the CCR2-64I variant became significant. Therefore the CCR2-64I variant was also studied in women with cervical pre-cancers and HPV infection. When the SIL positive (LSIL and HSIL positive) controls $(\mathrm{n}=91)$ were compared with the invasive cervical cancer cases $(\mathrm{n}=446)$ for CCR2-V64I polymorphism, a statistically significant association was found with the presence of CCR2-64I variant $(\mathrm{P}=0.001)$ in the invasive cancers adjusted for ethnicity and smoking (Table 2). This result indicated a difference in the CCR2-64I variant of women who developed invasive cancer compared to the women with pre-cancers.

Since the association was found with cancer it was then determined if the same association could be observed in pre-cancers within the control group. The association of CCR2-V64I polymorphism with abnormal cytology status, HSIL status and high risk HPV status was investigated in the control group. Both abnormal cytology $(\mathrm{P}=$ 0.437) (Table 3) and high risk HPV status $(\mathrm{P}=0.913)$ (Table 4) were not found to be associated with CCR2-64I variant in the control group adjusted for ethnicity and smoking. Comparing only the HSIL positive samples with all the normal cytology samples also did not show any significant association $(P=0.157)$ in controls adjusted for ethnicity and smoking (Table 5).

\section{Discussion}

Polymorphisms in the CCR2 gene that alters the macrophage recruitment have been reported to influence a number of diseases including AIDS [20-23], multiple sclerosis [24], breast cancer [25], carotid atherosclerosis [26] and renal transplant rejection [27]. This polymorphism has also been associated with cervical cancer in two different populations [28-31].

Persistent HPV infection of epithelial cells is necessary for the carcinogenesis of the uterine cervix, but not all HPV infected cervical lesions progress to cervical cancer. In addition many pre-cancers do not progress to invasive cancer and can regress. Chemokines are regarded as an 
Table 1: Counts (n), frequencies (\%) and association statistics for CCR2-V64I genotypes for cases and controls

\begin{tabular}{|c|c|c|c|c|c|c|}
\hline & \multicolumn{2}{|c|}{ Controls $(n=1378)$} & \multicolumn{2}{|c|}{ Cases $(n=446)$} & \multirow{2}{*}{\multicolumn{2}{|c|}{$\begin{array}{l}\text { Genotype-cervical cancer association, } \\
\text { adjusted for ethnicity and smoking }\end{array}$}} \\
\hline & Black $305(n=22)$ & $\begin{array}{l}\text { Mixed-ancestry } 1073 \\
\quad(n=78)\end{array}$ & Black $106(n=24)$ & $\begin{array}{l}\text { Mixed-ancestry } \\
340(n=76)\end{array}$ & & \\
\hline Genotypes & n (\%) & n (\%) & n (\%) & n (\%) & P-value & OR (95\% CI) \\
\hline \multicolumn{7}{|l|}{ CCR2 GTA } \\
\hline GG & $189(62)$ & $704(66)$ & $24(23)$ & $78(23)$ & - & 1 \\
\hline AG & $112(37)$ & $356(33)$ & $81(76)$ & $255(75)$ & 0.001 & $6.22(4.85-7.97)$ \\
\hline$A A$ & $4(1)$ & $13(1)$ & $1(1)$ & $7(2)$ & 0.002 & $3.99(1.68-9.50)$ \\
\hline$A G+A A$ & $116(38)$ & $369(34)$ & $82(77)$ & $262(77)$ & 0.001 & $6.14(4.79-7.86)$ \\
\hline
\end{tabular}

important cofactor in the progression of the cervical lesions to cancer of the cervix [7].

We are the first to study the frequency of the CCR2$V 64 I$ polymorphism in an indigenous black African as well as in a mixed-ancestry population. We found a statistically significant association of CCR2-64I variant $(\mathrm{P}=$ 0.001 ) with cervical cancer in African black and mixedancestry women adjusted for ethnicity and smoking. Our data suggests that women carrying A allele $(\mathrm{P}=0.001$, $\mathrm{OR}$ $(95 \% \mathrm{CI})=6.14(4.79-7.86))$ and $\mathrm{A} / \mathrm{A}$ genotype $(\mathrm{P}=0.002$, OR $(95 \% \mathrm{CI})=3.99(1.68-9.50))$ at position 190 of the CCR2 gene have increased risk of cervical cancer compared to women carrying the $G$ variant of it. When the SIL controls were compared with cervical cancer cases, it was found that CCR2-64I carriers are at more risk of developing cervical cancer $(\mathrm{P}=0.001$, OR $(95 \% \mathrm{CI})=6.86$ (4.19-11.21)) from SIL. The analysis of CCR2-V64I genotypes with abnormal cytology $(\mathrm{P}=0.437)$, presence of high risk HPV infection $(\mathrm{P}=0.913)$ and HSIL positive status $(\mathrm{P}=0.157)$ did not show any statistically significant association in the control group.

Our results showing susceptible effect of CCR2-64I variant to cervical cancer (compared to controls without cancer of the cervix and SIL positive controls) do not agree with those of two other groups, Coelho et al. [29] and Ivansson et al [30]. Also our data showing no association of CCR2-64I variant with HSIL when compared to individuals with normal cytology, do not confirm Coelho et. al. [28] who reported an increased risk of CCR2-64I variant with HSIL. The contradictory results might be due to one or several factors, including the difference in ethnic origin of the populations studied the difference in sample size and the high percentage of the mutant allele (CCR2-64I) in our population. The fact that we did not find any association with abnormal cytology, HSIL and high risk HPV infection in the control group but found a susceptible effect with cervical cancer suggests that CCR2-64I variant is not associated with susceptibility to $\mathrm{HPV}$ infection and pre-cancerous lesions in our popula-

Table 2: Association statistics for CCR2-V64I genotypes for cases and SIL positive controls

\begin{tabular}{|c|c|c|c|c|c|c|}
\hline \multirow[b]{3}{*}{ Genotypes } & \multicolumn{2}{|c|}{ SIL positive controls $(n=91)$} & \multicolumn{2}{|c|}{ Cases $(n=446)$} & & \\
\hline & \multirow{2}{*}{$\begin{array}{c}\text { Black } 31 \text { (34) } \\
\mathbf{n}(\%)\end{array}$} & \multirow{2}{*}{$\begin{array}{l}\text { Mixed-ancestry } 60 \text { (66) } \\
\mathrm{n}(\%)\end{array}$} & \multirow{2}{*}{$\begin{array}{c}\text { Black } 106(24) \\
n(\%)\end{array}$} & \multirow{2}{*}{$\begin{array}{l}\text { Mixed-ancestry } \\
340(76) \\
\mathbf{n}(\%)\end{array}$} & \multicolumn{2}{|c|}{$\begin{array}{l}\text { Genotype-cervical cancer } \\
\text { association, adjusted for ethnicity } \\
\text { and smoking }\end{array}$} \\
\hline & & & & & P-value & OR (95\% Cl) \\
\hline \multicolumn{7}{|l|}{ CCR2 GTA } \\
\hline GG & $21(68)$ & $40(66)$ & $24(23)$ & $78(23)$ & - & 1 \\
\hline AG & $9(29)$ & $19(32)$ & $81(76)$ & $255(75)$ & 0.001 & $7.18(4.35-11.87)$ \\
\hline$A A$ & $1(3)$ & $1(2)$ & $1(1)$ & $7(2)$ & 0.300 & $2.32(0.47-11.36)$ \\
\hline$A G+A A$ & $10(32)$ & $20(33)$ & $82(77)$ & $262(77)$ & 0.001 & $6.86(4.19-11.21)$ \\
\hline
\end{tabular}

Cases = Women with cancer of the cervix (ICC), SIL positive controls = Women without cancer of the cervix (ICC) but positive for LSIL and HSIL by pap smear test. 
Table 3: Association statistics for CCR2-V64I genotypes according to cytology in the control group

\begin{tabular}{|c|c|c|c|c|c|c|}
\hline & \multicolumn{2}{|c|}{ Normal cytology $(n=1070)$} & \multicolumn{2}{|c|}{ Abnormal cytology $(n=185)$} & & \\
\hline & Black $210(20)$ & $\begin{array}{l}\text { Mixed-ancestry } \\
860(80)\end{array}$ & Black 64 (35) & $\begin{array}{c}\text { Mixed-ancestry } \\
121(65)\end{array}$ & \multicolumn{2}{|c|}{$\begin{array}{l}\text { Genotype-abnormal cytology } \\
\text { association, adjusted for ethnicity and } \\
\text { smoking }\end{array}$} \\
\hline Genotypes & n (\%) & n (\%) & n (\%) & n (\%) & P-value & OR $(95 \% \mathrm{CI})$ \\
\hline \multicolumn{7}{|l|}{ CCR2 GTA } \\
\hline GG & $124(59)$ & $563(66)$ & $45(70)$ & $78(64)$ & - & 1 \\
\hline AG & $84(40)$ & $287(33)$ & $17(27)$ & $40(33)$ & 0.290 & $0.83(0.59-1.17)$ \\
\hline AA & $2(1)$ & $10(1)$ & $2(3)$ & $3(3)$ & 0.134 & $2.28(0.78-6.69)$ \\
\hline$A G+A A$ & $86(41)$ & $297(35)$ & $19(30)$ & $43(36)$ & 0.437 & $0.88(0.63-1.22)$ \\
\hline
\end{tabular}

tion but increases the risk of ICC at a later stage during the development of cancer of the cervix from HSIL (Figure 2). Our results showing no association of CCR2-64I variant with HPV infection are in line with the findings of Zheng B et. al [31].

HPV-infected epithelial cells do not elicit strong local or systemic immune responses. MCP-1 plays an important role in the development of tumours as it is one of the major chemokines that induces recruitment of macrophages in tumours including cervical cancer [14]. Recruitment and activation of macrophages is a vital process for the inflammatory response of the human body. Though macrophages display tumour cytotoxicity, tumour-associated macrophages (TAMs) mainly have protumour functions [38] and help in tumour angiogenesis. Increased expression of MCP-1 recruits more macrophages which speed up the process of tumour destruction or progression depending upon the type of macrophages recruited. After the infection of epithelial cells by HPV, the MCP-1 expression decreases from LSIL to HSIL and increases again from HSIL to ICC [17]. Tumour cells have been reported with high levels of
MCP-1 expression [18]. Macrophages which are recruited by MCP-1 chemokine, express CCR2 on their cell surface. The CCR2-64I variant is associated with increased expression of CCR2A (due to increased stability of CCR2A) on the cell surface of monocytes. This increases the attraction of monocytes to tumour cells producing MCP-1. In early stages of infection, the increased recruitment of monocytes results in more macrophages and associated cells (DC and NK cells) converging on the developing tumours to destroy the progressing tumours cells. Therefore, increased expression of CCR2 receptors results in increased recruitment of macrophages and possibly faster destruction of a developing tumour. Thus the CCR2-64I variant might be associated with reduced risk of developing cancer in the early phase. Our results with HPV infected individuals do point toward a reduced risk of CCR2-64I with abnormal cytology and HSIL positivity when compared to individuals with normal cytology (according to the tendencies of the ORs) though not statistically significant.

However, once the tumour cells evade the immune system, the macrophages that are recruited towards elimina-

Table 4: Association statistics for CCR2-V64I genotype for high risk HPV infection in the control group

\begin{tabular}{|c|c|c|c|c|c|c|}
\hline \multirow[b]{3}{*}{ Genotypes } & \multicolumn{2}{|c|}{ High risk HPV positive (201) } & \multicolumn{2}{|c|}{ High risk HPV negative (1053) } & \multirow{2}{*}{\multicolumn{2}{|c|}{$\begin{array}{l}\text { Genotype-high risk HPV association, } \\
\text { adjusted for ethnicity and smoking }\end{array}$}} \\
\hline & Black 62 (31) & $\begin{array}{c}\text { Mixed-ancestry } \\
139(69)\end{array}$ & Black 212 (20) & $\begin{array}{c}\text { Mixed-ancestry } 841 \\
(\mathbf{8 0})\end{array}$ & & \\
\hline & n (\%) & n (\%) & n (\%) & n (\%) & P-value & OR $(95 \% \mathrm{CI})$ \\
\hline \multicolumn{7}{|l|}{ CCR2 GTA } \\
\hline GG & $34(55)$ & $94(68)$ & $135(64)$ & $546(65)$ & - & 1 \\
\hline AG & $27(43)$ & $41(29)$ & $74(35)$ & $286(34)$ & 0.904 & $0.98(0.71-1.35)$ \\
\hline AA & $1(2)$ & $4(3)$ & $3(1)$ & $9(1)$ & 0.163 & $2.14(0.73-6.25)$ \\
\hline$A G+A A$ & $28(45)$ & $45(32)$ & $77(36)$ & $295(35)$ & 0.913 & $1.02(0.74-1.40)$ \\
\hline
\end{tabular}

High risk HPV positive = Positive for Hybrid Capture II HPV Test, High risk HPV negative = Negative for Hybrid Capture II HPV Test. 
Table 5: Association statistics for CCR2-V64I genotypes for HSIL in the control group

\begin{tabular}{|c|c|c|c|c|c|c|}
\hline \multirow[b]{3}{*}{ Genotypes } & \multicolumn{2}{|c|}{ Normal cytology $(n=1070)$} & \multicolumn{2}{|c|}{ HSIL positive $(n=45)$} & & \\
\hline & \multirow{2}{*}{$\begin{array}{c}\text { Black } 210(20) \\
n(\%)\end{array}$} & \multirow{2}{*}{$\begin{array}{l}\text { Mixed-ancestry } \\
860(80) \\
n(\%)\end{array}$} & \multirow{2}{*}{$\begin{array}{c}\text { Black } 16(36) \\
n(\%)\end{array}$} & \multirow{2}{*}{$\begin{array}{c}\text { Mixed-ancestry } \\
29(64) \\
n(\%)\end{array}$} & \multicolumn{2}{|c|}{$\begin{array}{l}\text { Genotype-HSIL association, } \\
\text { adjusted for ethnicity and smoking }\end{array}$} \\
\hline & & & & & P-value & OR $(95 \% \mathrm{Cl})$ \\
\hline \multicolumn{7}{|l|}{ CCR2 GTA } \\
\hline GG & $124(59)$ & $563(66)$ & $12(75)$ & $21(72)$ & - & 1 \\
\hline AG & $84(40)$ & $287(33)$ & $4(25)$ & $8(28)$ & 0.190 & $0.64(0.32-1.25)$ \\
\hline AA & $2(1)$ & $10(1)$ & $0(0)$ & $0(0)$ & - & - \\
\hline$A G+A A$ & $86(41)$ & $297(35)$ & $4(30)$ & $8(28)$ & 0.157 & $0.61(0.31-1.21)$ \\
\hline
\end{tabular}

HSIL positive = Positive for HSIL by pap smear test, Normal cytology = Negative for pap smear test.

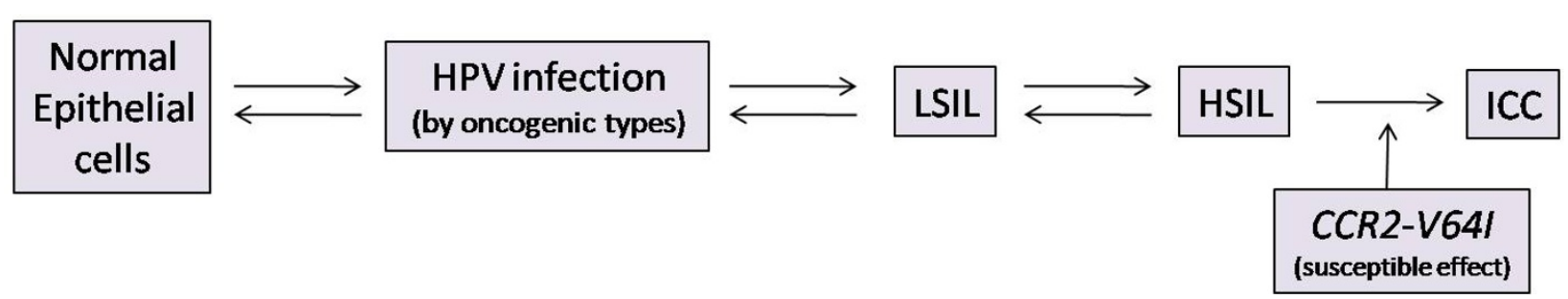

Figure 2 A schematic diagram showing the susceptible effect of CCR2-64I variant during development of ICC

tion of the tumour switch to TAMs [15,16]. The increased stability of CCR2A due to CCR2-64I variant sustains the tumours by continuously recruiting TAMs that support tumour angiogenesis. It is not known when this switch from tumour cytotoxic macrophages to TAMs occurs during the development of cervical cancer. We hypothesize that the switch occurs during early phase of HSIL. Thus the CCR2-64I variant would be associated with increased risk of cancer in the later stage of tumour development (in this situation after progressing to HSIL) when compared to the CCR2-64 V variant which is associated with less stable CCR2A stability and expression.

\section{Conclusions}

Our study showed a significant association of CCR2-V64I polymorphism with cervical cancer, but did not show any association with HPV infection and pre-cancerous lesions. CCR2-64I variant showed an increased risk of cervical cancer but not with infection by HPV and precancerous lesions. This implies that this mutation is associated with a late event in the progression to cervical cancer. Further studies are needed with patients in different stages of cervical cancer to confirm our findings.

\section{Competing interests}

The authors declare that they have no competing interests.

\section{Authors' contributions}

KC participated in planning of the study, performed extraction of DNA, genotyping, analyzing the results and advanced statistical analysis. CD helped in sta- tistical analysis and interpreting of the results. $\mathrm{MH}$ coordinated the collection of the biological samples. ALW was responsible for the storage of the biological samples, helped in planning and supervising the study and helped in interpretation of the results. All authors critically read and took part in finalizing the manuscript.

\section{Acknowledgements}

We are grateful to all the patients and controls who participated in this study. We thank Professor Ulf Gyllensten (Sweden) for the suggestion that we studied this polymorphism. We would also like to extend a special thank to Dr. Zenda Woodman and Helba Bredel for their valuable technical advice. This work is based upon research supported by the South African Research Chairs Initiative of the Department of Science and Technology and National Research Foundation. It was also supported by the NRF South Africa/Sweden Science and Technology Agreement's Fund.

\section{Author Details}

'Division of Medical Virology and Institute of Infectious Disease and Molecular Medicine (IIDMM), University of Cape Town, Cape Town, Republic of South Africa, 2Division of Human Genetics, Faculty of Health Sciences, University of Cape Town, Cape Town, Republic of South Africa, ${ }^{3}$ School of Public Health and Family Medicine, University of Cape Town, Cape Town, Republic of South Africa and ${ }^{4}$ National Health Laboratory Service, Groote Schuur Hospital, Observatory, Cape Town, Republic of South Africa

Received: 29 December 2009 Accepted: 10 June 2010

Published: 10 June 2010

\section{References}

1. Castellsague X, Sanjose de S, Aguado T, Louie KS, Bruni L, Munoz J, Diaz M, Irwin K, Gacic M, Beauvais O, Albero G, Ferrer E: HPV and cervical cancer in the world 2007 report. Vaccine 2007:S3.

2. Anorlu RI: Cervical cancer: the sub-Saharan African perspective. Reprod Health Matters 2008, 16:41-49.

3. Parkin DM, Ferlay J, Hamdi-Chérif M, Sitas F, Thomas JO, Wabinga H, Whelan SL: Cancer in Africa: Epidemiology and Prevention. In IARC Scientific Publications No 153 Lyon: IARC Press; 2003. 
4. Rohan TE, Burk RD, Franco EL: Toward a reduction of the global burden of cervical cancer. Am J Obstet Gynecol 2003, 189:S37-S39.

5. Snijders PJ, Steenbergen RD, Heideman DA, Meijer CJ: HPV-mediated cervical carcinogenesis: concepts and clinical implications. J Pathol 2006, 208:152-164.

6. Kobayashi A, Greenblatt RM, Anastos K, Minkoff H, Massad LS, Young M, Levine AM, Darragh TM, Weinberg V, Smith Mc-Cune KK: Functional attributes of mucosal immunity in cervical intraepithelial neoplasia and effects of HIV infection. Cancer Res 2004, 64:6766-6774.

7. Tindle RW: Immune evasion in human papillomavirus-associated cervical cancer. Nat Rev Cancer 2002, 2:59-65.

8. Martin CM, Kehoe L, Spillane CO, O'Leary JJ: Gene discovery in cervical cancer: towards diagnostic and therapeutic biomarkers. Mol Diagn Ther 2007, 11:277-290

9. Magnusson PK, Sparen P, Gyllensten UB: Genetic link to cervical tumours. Nature 1999, 400:29-30.

10. zur Hausen $\mathrm{H}$ : Papillomaviruses and cancer: from basic studies to clinical application. Nat Rev Cancer 2002, 2:342-350.

11. Um SJ, Rhyu JW, Kim EJ, Jeon KC, Hwang ES, Park JS: Abrogation of IRF-1 response by high-risk HPV E7 protein in vivo. Cancer Lett 2002, 179:205-212.

12. Kurihara T, Warr G, Loy J, Bravo R: Defects in macrophage recruitment and host defense in mice lacking the CCR2 chemokine receptor. J Exp Med 1997, 186:1757-1762.

13. MacKay CR: Chemokines: immunology's high impact factors. Nat Immunol 2001, 2:95-101.

14. Vicari AP, Caux C: Chemokines in cancer. Cytokine Growth Factor Rev 2002, 13:143-154.

15. Lamagna C, urrand-Lions M, Imhof BA: Dual role of macrophages in tumor growth and angiogenesis. J Leukoc Biol 2006, 80:705-713.

16. Lin EY, Pollard JW: Tumor-associated macrophages press the angiogenic switch in breast cancer. Cancer Res 2007, 67:5064-5066.

17. Riethdorf L, Riethdorf S, Gutzlaff K, Prall F, Loning T: Differential expression of the monocyte chemoattractant protein-1 gene in human papillomavirus-16-infected squamous intraepithelial lesions and squamous cell carcinomas of the cervix uteri. Am J Pathol 1996, 149:1469-1476.

18. Kleine-Lowinski K, Gillitzer R, Kuhne-Heid R: Monocyte-chemoattractant-protein-1 (MCP-1)-gene expression in cervical intraepithelial neoplasias and cervical carcinomas. Int J Cancer 1999, 82:6-11.

19. Nakayama EE, Tanaka Y, Nagai Y, Iwamoto A, Shioda T: A CCR2-V64| polymorphism affects stability of CCR2A isoform. AIDS 2004, 18:729-738

20. Ioannidis JP, Rosenberg PS, Goedert JJ, Ashton $\sqcup$, Benfield TL, Buchbinder $S P$, Coutinho RA, Eugen-Olsen G, Gallart T, Katzenstein TL, Kostrikis LG, Kuipers H, Louie LG, Mallal SA, Margolick JB, Martinez OP, Meyer L, Michael NL, Operskalski E, Pantaleo G, Rizzardi GP, Schuitemaker H, Sheppard HW, Stewart GJ, Theodorou ID, Ullum H, Vicenzi E, Vlahov D, Wilkinson D, Workman C, et al:: Effects of CCR5-Delta32 CCR2-64I and SDF-1 3'A alleles on HIV-1 disease progression: An international meta-analysis of individual-patient data. Ann Intern Med 2001, 135:782-795.

21. Smith MW, Dean M, Carrington M, Winkler C, Huttley GA, Lomb DA, Goedert JJ, O'Brien TR, Jacobson LP, Kaslow R, Buchbinder S, Vittinghoff E, Vlahov D, Hoots K, Hilgartner MW, O'Brien SJ: Contrasting genetic influence of CCR2 and CCR5 variants on HIV-1 infection and disease progression. Hemophilia Growth and Development Study (HGDS) Multicenter AIDS Cohort Study (MACS) Multicenter Hemophilia Cohort Study (MHCS) San Francisco City Cohort (SFCC) ALIVE Study. Science 1997, 277:959-965.

22. Mulherin SA, O'Brien TR, loannidis JP, Goedert JJ, Buchbinder SP, Coutinho RA, Jamieson BD, Meyer L, Michael NL, Pantaleo G, Rizzardi GP, Schuitemaker H, Sheppard HW, Theodorou ID, Vlahov D, Rosenberg PS: Effects of CCR5-Delta32 and CCR2-64I alleles on HIV-1 disease progression: the protection varies with duration of infection. AIDS 2003, 17:377-387.

23. Doms RW, Peiper SC: Unwelcomed guests with master keys: how HIV uses chemokine receptors for cellular entry. Virology 1997, 235:179-190

24. Miyagishi R, Niino M, Fukazawa T, Yabe I, Kikuchi S, Tashiro K: C-C chemokine receptor 2 gene polymorphism in Japanese patients with multiple sclerosis. J Neuroimmunol 2003, 145:135-138.
25. Zafiropoulos A, Crikas N, Passam AM, Spandidos DA: Significant involvement of CCR2-64I and CXCL12-3a in the development of sporadic breast cancer. J Med Genet 2004, 41:e59.

26. Nyquist PA, Winkler CA, McKenzie LM, Yanek LR, Becker LC, Becker DM: Single nucleotide polymorphisms in monocyte chemoattractant protein-1 and its receptor act synergistically to increase the risk of carotid atherosclerosis. Cerebrovasc Dis 2009, 28:124-130.

27. Omrani MD, Mokhtari MR, Tagizadae A, Bagheri M, hmad-Poor P: Association of CCR5-59029 A/G and CCR2-V64I variants with renal allograft survival. Iran J Immunol 2008, 5:201-206.

28. Coelho A, Matos A, Catarino R, Pinto D, Sousa H, Pereira D, Medeiros R: The influence of chemokine receptor CCR2 genotypes in the route to cervical carcinogenesis. Gynecol Obstet Invest 2007, 64:208-212.

29. Coelho A, Matos A, Catarino R, Pinto D, Pereira D, Lopes C, Medeiros R: Protective role of the polymorphism CCR2-64l in the progression from squamous intraepithelial lesions to invasive cervical carcinoma. Gynecol Oncol 2005, 96:760-764.

30. Ivansson EL, Gustavsson IM, Magnusson JJ, Steiner LL, Magnusson PK, Erlich HA, Gyllensten UB: Variants of chemokine receptor 2 and interleukin 4 receptor but not interleukin 10 or Fas ligand increase risk of cervical cancer. Int J Cancer 2007, 121:2451-2457.

31. Zheng B, Wiklund F, Gharizadeh B, Sadat M, Gambelunghe G, Hallmans G, Dillner J, Wallin KL, Ghaderi M: Genetic polymorphism of chemokine receptors CCR2 and CCR5 in Swedish cervical cancer patients. Anticancer Res 2006, 26:3669-3674.

32. Ahlbom A, Lichtenstein $P$, Malmstrom $H$, Feychting M, Hemminki K, Pedersen NL: Cancer in twins: genetic and nongenetic familial risk factors. J Natl Cancer Inst 1997, 89:287-293.

33. Hemminki K, Dong C, Vaittinen P: Familial risks in cervical cancer: is there a hereditary component? Int J Cancer 1999, 82:775-781.

34. Tishkoff SA, Reed FA, Friedlaender FR, Ehret $C$, Ranciaro A, Froment A, Hirbo JB, Awomoyi AA, Bodo JM, Doumbo O, Ibrahim M, Juma AT, Kotze MJ, Lema G, Moore JH, Mortensen H, Nyambo TB, Omar SA, Powell K, Pretorius GS, Smith MW, Thera MA, Wambebe C, Weber JL, Williams SM: The genetic structure and history of Africans and African Americans. Science 2009, 324:1035-1044.

35. Shapiro S, Rosenberg L, Hoffman M, Kelly JP, Cooper DD, Carrara H, Denny LE, du Toit G, Allan BR, Stander IA, Williamson AL: Risk of invasive cancer of the cervix in relation to the use of injectable progestogen contraceptives and combined estrogen/progestogen oral contraceptives (South Africa). Cancer Causes Control 2003, 14:485-495.

36. Hoffman M, Cooper D, Carrara H, Rosenberg L, Kelly J, Stander I, Williamson AL, Denny L, du Toit G, Shapiro S: Limited Pap screening associated with reduced risk of cervical cancer in South Africa. Int $J$ Epidemiol 2003, 32:573-577.

37. Tang J, Rivers C, Karita E, Costello C, Allen S, Fultz PN, Schoenbaum EE, Kaslow RA: Allelic variants of human beta-chemokine receptor 5 (CCR5) promoter: evolutionary relationships and predictable associations with HIV-1 disease progression. Genes Immun 1999, 1:20-27.

38. Mantovani A, Bottazzi B, Colotta F, Sozzani S, Ruco L: The origin and function of tumor-associated macrophages. Immunol Today 1992 13:265-270

\section{Pre-publication history}

The pre-publication history for this paper can be accessed here: http://www.biomedcentral.com/1471-2407/10/278/prepub

doi: 10.1186/1471-2407-10-278

Cite this article as: Chatterjee et al, CCR2-V64l polymorphism is associated with increased risk of cervical cancer but not with HPV infection or pre-cancerous lesions in African women BMC Cancer 2010, 10:278 